\title{
ANALISIS PERAMALAN PRODUKSI ROTI PADA GOLDEN BAKERY DI KOTA TERNATE
}

\author{
Hamka* dan Yonette Maya Tupamahu* \\ Staf Pengajar Faperta UMMU-Ternate \\ Email : hamka_agb@yahoo.co.id,ymtup@yahoo.co.id
}

\begin{abstract}
ABSTRAK
Penelitian ini bertujuan mendapatkan metode peramalan penjualan roti yang tepat di Golden Bakery untuk 3 bulan ke depan. Mengingat banyaknya jenis roti yang diproduksi maka penelitian ini dibatasi untuk roti tawar sisir dan cokelat sisir. Metode peramalan yang digunakan, yaitu: metode rata-rata sederhana (simple average), metode rata-rata bergerak (moving average), metode pemulusan eksponensial (simple exponential smoothing). Peramalan penjualan roti tiga bulan yang akan datang menggunakan metode yang terbaik, yaitu metode yang menghasilkan nilai kesalahan terkecil. Metode kesalahan peramalan yang digunakan yaitu The Mean Absolute Percentage Error (MAPE) dan Mean Squared Error (MSE). Hasil penelitian menunjukkan metode Simple Average memiliki nilai MSE terkecil yaitu 580 dan nilai peramalan produksi adalah 906. Berdasarkan pendekatan nilai MSE maka Golden Bakery dapat memprediksi produksi selama 3 bulan ke depan dengan pendekatan Simple Average sebesar 906 buah roti tiap bulannya. Sedangkan untuk roti cokelat sisir, maka metode Simple Average memiliki nilai MSE terkecil yaitu 762 dan peramalan produksi untuk 3 bulan mendatang sebesar 1016 buah.
\end{abstract}

Keyword : roti, peramalan, produksi

\section{PENDAHULUAN}

\subsection{Latar Belakang}

Manusia belajar seni membuat roti lebih dari 4000 tahun yang lalu. Padahal tidak selalu dalam bentuk yang sama atau seperti yang kita ketahui sekarang, roti telah menjadi bahan pokok makanan yang populer untuk semua usia. Konsumsi roti yang hampir di mana-mana menempatkannya dalam posisi kepentingan global dalam nutrisi internasional (Barret, 1975 dalam Gellynck, et al., 2008). Produk roti bervariasi luas di seluruh dunia, seperti halnya teknik produksinya. Bahan dasarnya adalah tepung sereal, air, ragiatau bahan ragi lain, dan garam (Sluimer, 2005).

Roti adalah makanan pokok di negara berkembang. Roti dikonsumsi dalam jumlah yang relatif besar oleh segala golongan masyarakat karena terjangkau dan tersedia dalam bentuk "siap makan" (Darko, 2002). Roti bisa didapatkan dimana saja, di toko-toko, pasar-pasar swalayan, atau warung, kios kecil, dan bahkan pedagang keliling. Luasnya pemasaran roti dan tingginya minat konsumen akan roti mengindikasikan bahwa persaingan produsen akan terjadi.

Persaingan penjualan roti bisa berimpikasi pada tingkat produksi yang relatif tidak stabil, dimana produsen akan kesulitan memprediksi tingkat permintaan akan roti yang diproduksinya. Golden Bakery adalah salah satu perusahaan roti di Kota Ternate yang memenuhi kebutuhan masyarakat Kota Ternate akan roti sejak tahun 2008 dimana dalam proses produksinya diperhadapkan pada ketidakpastian permintaan akan roti, yang mengakibatkan jumlah yang diproduksi pun tidak pasti jumlahnya.

Selama ini jumlah dan jenis roti yang akan diproduksi mengandalkan intuisi dan pengalaman dari bagian produksi. Hal inilah yang menyebabkan perusahaan mengalami kesulitan dalam memperkirakan tingkat kebutuhan permintaan roti di Kota Ternate. 
Oleh karena itu peramalan produksi dengan menggunakan metode deret waktu dan kausal diharapkan bisa menjadi acuan bagi perusahaan untuk melakukan prediksi jumlah roti yang harus diproduksi dan dapat diserap oleh pasar. Mengingat banyaknya jenis roti yang diproduksi maka penelitian ini dibatasi pada produk roti tawar sisir dan roti cokelat sisir dan peramalan untuk jangka waktu 3 bulan mendatang.

\subsection{Tujuan dan Manfaat Penelitian}

Penelitian ini memiliki tujuan yaitu untuk mendapatkan metode peramalan penjualan yang tepat pada penjualan roti. Manfaat penelitian ini adalah memberikan informasi bagi produsen mengenai metode peramalan yang tepat untuk memproduksi roti sehingga meminimalkan resiko usaha.

\section{METODE PENELITIAN}

\subsection{Waktu dan Tempat Penelitian}

Penelitian dilaksanakan pada bulan April - Oktober 2016 di Golden Bakery, Kota Ternate. Lokasi penelitian dipilih secara purposive dengan pertimbangan bahwa Golden Bakery adalah salah satu perusahaan roti yang sudah cukup dikenal oleh masyarakat di Kota Ternate

\subsection{Data dan Sumber Data}

Data yang digunakan dalam penelitian ini adalah data primer yang bersumber dari bagian pemasaran perusahaan. Data yang digunakan adalah jumlah produksi kedua jenis roti dari bulan April 2015 sampai bulan April 2016.

\subsection{MetodeAnalisis Data}

Peneliti terdahulu telah menggunakan beberapa metode peramalan yaitu metode exponential smoothing, antara lain: Situmorang, dkk (2015) memprediksi produksi kakao; Sukmarani, dkk (2016) meneliti jumlah roti yang akan diproduksi pada suatu perusahaan roti di Kendari. Gusdian, dkk (2016) memakai metode exponential smoothing dan moving average untuk ramalan permintaan produk roti pada industri "Tiara Rizki" di Kota Palu.

Merujuk penelitian terdahulu maka untuk menjawab tujuan penelitian digunakan metode rata-rata sederhana (simple average), metode rata-rata bergerak (moving average), metode pemulusan eksponensial (simple exponential smoothing).

\section{Metode Simple Average}

Merupakan metode yang mengambil rata-rata dari seluruh data observasi yang dikumpulkan untuk meramalkan data yang akan datang (Hanke, et. al., 2005).

Persamaannya adalah:

$$
X=1 / T\left(X_{1}+X_{2}+X_{3}+\ldots+X_{t}\right)
$$

dimana:

$X$ = data peramalan yang akan datang

$X_{t}=$ data observasi pada periode ke $t$

$\mathrm{T}=$ jumlah periode observasi

2. Metode Moving Average

Moving Average digunakan untuk menggambarkan pendekatan ini. Setiap observasi baru menjadi tersedia, sebuah ratarata baru dihitung dengan menjumlahkan nilai paling baru dan mengeluarkan yang paling tua. Moving average ini lebih digunakan untuk meramalkan periode selanjutnya. Persamaan menunjukkan peramalan moving average (Hanke, et. al., 2005).

$$
\begin{aligned}
& Y_{t+1}=Y_{t}+Y_{t-1}+\cdots+Y_{t-k^{+1}} / k \\
& e_{t}=Y_{t}-Y_{t}
\end{aligned}
$$

Dimana :

$Y_{t+1}=$ nilai peramalan untuk periode selanjutnya

$Y_{t} \quad=$ nilai sebenarnya pada periode $\mathbf{t}$

$k \quad=$ jumlah perlakuan dalam moving average

\section{Metode Simple Exponential Smoothing}

Peramalan menggunakan metode pemulusan eksponensial dilakukan berdasarkan formula berikut (Hanke, et. al., 2005) :

$$
\mathrm{F}_{\mathrm{t}}=\mathrm{F}_{\mathrm{t}-1}+\alpha\left(\mathrm{A}_{\mathrm{t}-1}-\mathrm{F}_{\mathrm{t}-1}\right)
$$

dimana:

$F_{t}=$ Nilai ramalan untuk periode waktu ke-t

$\mathrm{F}_{\mathrm{t}-1}=$ Nilai ramalan untuk satu periode waktu yang lalu

$\alpha \quad=$ Koefisien pemulusan

$A_{t-1}=$ Nilai aktual untuk satu periode waktu yang lalu

Singh, et al (2015) melakukan penelitian peramalan permintaan boot untuk industri 
sepatu. Tujuan penelitiannya adalah untuk mengidentifikasi metode peramalan kuantitatif terbaik berdasar pada tingkat akurasi dan kemudahan dalam penggunaannya. Lebih lanjut Singh, et al (2015) menyatakan metode peramalan akan dipilih berdasarkan tingkat kesalahan peramalan (forecast error). Semakin kecil kesalahan peramalan, maka semakin akurat metode peramalan.

Menurut Silver, et al. (1998) bahwa pengukuran yang paling sering digunakan untuk akurasi model peramalan adalah kesalahan kuadrat rata-rata (MSE). Alasan mengapa MSE banyak digunakan karena terhubung langsung ke variasi kesalahan. Ukuran lainnya disarankan oleh Hyndman dan Koehler (2006) adalah Mean Absolute Percentage Error (MAPE). MAPE berlawanan dengan satuan ukuran MSE dan MAE karena dinyatakan dalam persentase. Sebagian besar buku teks merekomendasikan penggunaan MAPE dan itu adalah ukuran utama dalam M-kompetisi (Makridakis, et.al., 1982).

Sukmarani, dkk.(2016) dalam penelitiannya menerapkan metode Exponential smoothing pada peramalan penjualan dalam penentuan kuantitas produksi roti ini dapat ditambah persamaan ukuran statistik nilai kesalahan seperti Mean Error (MA), Mean Absolut Error (MAE) dan Sum Of Squared Error (MAPE).

Berdasarkan penelitian terdahulu maka penelitian ini akan menggunakan metode kesalahan peramalan The Mean Absolute Percentage Error (MAPE) dan Mean Squared Error (MSE). Pengolahan data menggunakan program WinQSB, pemilihan program tersebut dengan alasan bahwa program WinQSB mutahir dalam penyelesaian peramalan.

1. The Mean Absolute Percentage Error (MAPE)

The Mean Absolute Percentage Error (MAPE) digunakan untuk mengukur ketepatan nilai dugaan model yang dinyatakan dalam bentuk rata-rata persentase absolut kesalahan (Hanke, et. al., 2005).

$$
M A P E=\frac{1}{n} \sum_{i=1}^{n} \frac{\left[Y_{t}-\widehat{Y}_{t}\right]}{Y_{t}}
$$

Keterangan :

MAPE = The Mean Absolute Percentage Error

n $=$ Jumlah sampel

$Y_{t} \quad=$ Nilai aktual pada periode waktu $t$.

$\widehat{Y_{t}} \quad=$ Nilai ramalan untuk periode waktu $t$

\section{Mean Squared Error (MSE)}

Mean Squared Error (MSE) adalah metode lain untuk mengevaluasi metode peramalan. Masing-masing kesalahan atau sisa dikuadratkan kemudian dijumlahkan dan ditambahkan dengan jumlah observasi (Hanke, et. al., 2005).

$$
M S E=\frac{1}{n} \sum_{i=1}^{n}\left(Y_{t}-\widehat{Y}_{t}\right)^{2}
$$

Keterangan :

$$
\begin{array}{ll}
\text { MSE } & =\text { Mean Squared Error } \\
\mathbf{n} & =\text { Jumlah sampel } \\
Y_{t} & =\text { Nilai aktual pada periode waktu } t \\
\widehat{Y}_{t} & =\text { Nilai ramalan untuk periode waktu } \\
& t
\end{array}
$$

Setelah nilai The Mean Absolute Percentage Error (MAPE) dan Mean Squared Error (MSE) dari ketiga metode didapatkan, maka akan dilakukan komparasi terhadap nilai MAPE dan MSE terkecil sebagai hasil peramalan yang terbaik.

\section{HASIL DAN PEMBAHASAN}

Hasil peramalan produksi roti tawar di Golden Bakery untuk 3 bulan dapat dilihat pada Tabel 1. Tabel 1 memperlihatkan bahwa terdapat perbedaan peramalan roti tawar untuk 3 bulan mendatang, dimana metode Simple Average meramalkan penjualan roti tawar sebanyak 906 buah, metode Moving Average sebesar 891 buah, dan metode Exponential Smoothing sebesar 898 buah. Hasil ini menunjukkan metode Simple Average meramalkan jumlah penjualan yang lebih banyak dari pada kedua metode lainnya, disusul metode Exponential Smoothing dan metode Moving Average.

Pendekatan untuk melihat hasil peramalan yang terbaik dan dijadikan dasar bagi perusahaan dalam menentukan jumlah penjualan tersaji pada Tabel 2. 
Tabel 1. Peramalan Roti Tawar Sisir menggunakan metode Simple Average, Moving Average dan Exponential Smoothing untuk peramalan 3 bulan, 2016.

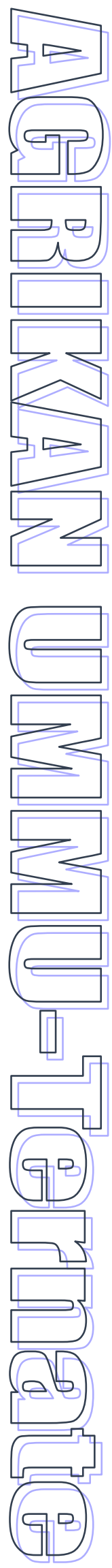

\begin{tabular}{cccc}
\multicolumn{4}{c}{ Exponential Smoothing untuk peramalan 3 bulan, 2016. } \\
\multirow{2}{*}{ Bulan } & \multicolumn{3}{c}{ Metode Time Serial } \\
\cline { 2 - 4 } & Simple Average & Moving Average & Exponential Smoothing \\
\hline Mei & 906 & 891 & 898 \\
Juni & 906 & 891 & 898 \\
Juli & 906 & 891 & 898
\end{tabular}

Sumber : Data Primer Setelah diolah, 2016

Tabel 2. Verifikasi Peramalan Roti Tawar Sisir Menggunakan Metode, Moving Average dan Exponential Smoothing untuk Peramalan 3 bulan, Tahun 2016

\begin{tabular}{cccc}
\hline Verifikasi & \multicolumn{4}{c}{ Metode Time Serial } \\
\cline { 2 - 4 } Peramalan & Simple Average & Moving Average & Exponential Smoothing \\
\hline MSE & 580 & 655 & 778 \\
\hline MAPE & 2,3 & 2,4 & 2,7
\end{tabular}

Sumber: Data Primer Setelah diolah,2016

Berdasarkan hasil verifikasi model penjualan roti untuk 3 bulan mendatang adalah peramalan diperoleh bahwa nilai MSE terkecil metode Simple Average dengan nilai peramalan adalah 580, dengan rata-rata presentase absolut roti tawar sisir untuk 3 bulan mendatang kesalahan sebesar MPE 2.3\%. Jika sebesar 906 buah.

menggunakan pendekatan MSE terkecil maka Sedangkan peramalan roti coklat sisir metode peramalan yang tepat dan bisa juga menggunakan ketiga metode peramalan, digunakan oleh perusahaan untuk meramalkan hasilnya sebagai berikut :

Tabel 3. Peramalan Roti Cokelat Sisir menggunakan metode Simple Average, Moving Average dan Exponential Smoothing untuk peramalan 3 bulan, 2016.

\begin{tabular}{cccc}
\hline \multirow{2}{*}{ Bulan } & \multicolumn{3}{c}{ Metode Time Serial } \\
\cline { 2 - 4 } & Simple Average & Moving Average & Exponential Smoothing \\
\hline Mei & 1016 & 1005 & 1010 \\
Juni & 1016 & 1005 & 1010 \\
Juli & 1016 & 1005 & 1010 \\
\hline
\end{tabular}

Sumber : Data Primer Setelah diolah, 2016

Tabel 3 menunjukkan adanya perbedaan peramalan dari ketiga metode ini, dimana Metode Simple Average meramalkan jumlah penjualan yang lebih banyak dari pada kedua metode lainnya sebesar 1016, disusul Metode Simple Exponential Smoothing sebesar 1010 dan Metode Moving Average sebesar 1005. Pendekatan yang dapat digunakan untuk melihat hasil peramalan yang terbaik dan dijadikan dasar bagi perusahaan dalam menentukan jumlah penjualan adalah dengan melihat nilai The Mean Absolute Percentage Error (MAPE) dan Mean Squared Error (MSE) dari tiap-tiap metode peramalan. Adapun hasil MSE dan MAPE dari ketiga metode peramalan adalah sebagai berikut :

Tabel 4. Verifikasi Peramalan Roti Cokelat Sisir Menggunakan Metode Moving Average dan Exponential Smoothing untuk Peramalan 3 bulan, Tahun 2016

\begin{tabular}{cccc}
\hline Verifikasi & \multicolumn{3}{c}{ Metode Time Serial } \\
\cline { 2 - 4 } Peramalan & Simple Average & Moving Average & Exponential Smoothing \\
\hline MSE & 762 & 976 & 1084 \\
MAPE & 2,4 & 2,5 & 2,8 \\
\hline
\end{tabular}

Sumber : Data Primer Setelah diolah,2016

Hasil verifikasi model peramalan diperoleh bahwa nilai MSE terkecil adalah 762, dengan rata-rata persentase absolut kesalahan sebesar MPE 2,4\%. Jika menggunakan pendekatan MSE terkecil maka metode peramalan yang tepat dan bisa digunakan oleh 
perusahaan untuk meramalkan penjualan roti untuk 3 bulan mendatang adalah metode Simple Average dengan nilai peramalan roti 1016 buah.

\section{PENUTUP}

Berdasarkan hasil penelitian dapat disimpulkan bahwa penjualan roti tawar sisir untuk 3 bulan mendatang menggunakan metode peramalan terbaik yaitu Simple Average, dengan nilai peramalan roti tawar sisir sebesar 906 buah. Sedangkan penjualan roti cokelat sisir untuk 3 bulan mendatang menggunakan metode peramalan terbaik Simple Average, dengan nilai peramalan roti cokelat sisir sebesar 1016 buah. Disarankan agar perusahaan atau produsen dapat menerapkan metode simple average untuk menentukan peramalan penjualan roti 3 bulan mendatang, karena dari hasil analisis metode ini yang paling mendekati aktual dan memiliki $M S E$ dan MAPE terkecil.

\section{DAFTAR PUSTAKA}

Arsyad, L., 1995. PeramalanBisnis. Badan Penerbit Fakultas Ekonomi, Yogyakarta.

Bowerman, B. L., O'Connell, R. T., \& Koehler, A. B., 2004. Forecasting, Time Series And Regression: An Applied Approach. Belmont, CA7 Thomson Brooks/Cole.

Darko K.O. 2002.The Role of Street Food Vendors in the Transmission of Enteric - 547.Pathogens, Ghana Medical Journal Bulletin of the World Health Organization pp.546

Gellynck, X., Kühne, B., Van Bockstaele, F, Van de Walle, D and Dewettinck, K., 2008. Consumer Perception of Bread Quality, 12th Congress of the European Association of Agricultural Economists - EAAE 2008

Gusdian, Eby, Abdul Muis, Arifuddin Lamusa, 2016. Peramalan Permintaan Produk Roti Pada Industri "Tiara Rizki" Di Kelurahan Boyaoge Kecamatan Tatanga Kota Palu, E-J. Agrotekbis 4 (1) :97-105, Februari 2016

Hanke, John,W. Wichern Dean, 2005. Business Forecasting, Pearson Education, Inc.

Hyndman, R. J., Koehler, A. B., 2006. Another Look At Measures Of Forecast Accuracy, International Journal of Forecasting, 22(4): p. 679-688

Makridakis, S., Anderson, A., Carbone, R., Fildes, R., Hibon, M., \& Lewandowski, R., et al. ,1982. The Accuracy Of Extrapolation (Time Series) Methods: Results Of A Forecasting Competition. Journal of Forecasting, 1, 111 - 153.

Rabbab, 2002.AnalisisPengendalian Persediaan Bahan Baku ProdukRotidi CenralFamily BakeryCinere,Jakarta, Skripsi, Jurusan Ilmu-ilmu Sosial Ekonomi Pertanian,Fakultas Pertanian,Institut Pertanian Bogor.

Silver, E., Pyke, D., Peterson, R., 1998.Inventory Management and Production Planning and Scheduling, Wiley, Toronto, p. 126.

Singh, Amrit Pal , Manoj Kumar Gaur, Dinesh Kumar Kasdekar and Sharad Agrawal, 2015. A Study of Time Series Model for Forecasting of Boot in Shoe Industry, International Journal of Hybrid Information Technology Vol.8, No.8 (2015), pp.143-152

Situmorang, Boldson Herdianto, Arie Qur'ania, Dian Asri Sukmawati, 2015. The Application of Prediction of Cocoa Yields with Exponential Smoothing Method, International Conference on Electrical Engineering, Informatics, and Its Education 2015

Sugiyono, 2010. Metode Penelitian Bisnis (Pendekatan Kuantitatif, Kualitatif dan R\&D), Alfabeta, Bandung.

Sluimer, P, 2005. Principles of Breadmaking: Functionality of Raw Materials and Process Steps, AACC, St. Paul.

Sukmarani, Ni Putu Yuli, Statiswaty, Rahmat Ramadhan, Penerapan Metode Exponential Smoothing Pada Peramalan Penjualan Dalam Penentuan Kuantitas Produksi Roti (Studi Kasus Perusahaan Roti Dhiba Kendari), Semantik, Vol.2, No.1, Jan-Jun 2016, pp. 229-236 